J. Clin. Chem. Clin. Biochem.

Vol. 28, 1990, pp. $413-417$

(C) 1990 Walter de Gruyter \& Co. Berlin · New York

\title{
HLA Class I-, Complement C4- and 21-Hydroxylase Probes in the Genetic Analysis of 21-Hydroxylase Deficiency
}

\author{
By L. Kochhan ${ }^{1}$, Sigrid Janssen ${ }^{1}$, D. Knorr ${ }^{2}, K$. Olek $^{1}$ and F. Bidlingmaier ${ }^{1}$ \\ ${ }^{1}$ Institut für Klinische Biochemie der Universität Bonn \\ 2 Kinderklinik der Universität München
}

(Received August 21, 1989/March 19, 1990)

\begin{abstract}
Summary: In order to develop an optimal strategy for the prenatal diagnosis of steroid 21-hydroxylase (EC 1.14.99.10) deficiency, we investigated 16 affected families with salt wasting syndrome. Genomic DNA derived from peripheral white blood cells was digested with 6 different restriction enzymes. Hybridisation was carried out with DNA-probes of the HLA class I region, the 21-hydroxylase- and the complement C4 genes. All the families were informative in at least three different loci. Twelve out of the 16 families were informative by neutral polymorphisms or disease related variants of the 21 -hydroxylase gene or the adjoining $\mathrm{C} 4$ locus. The reliability of prediction in these cases exceeded $99 \%$. The remaining 4 families were informative only in the HLA class I region, tantamount to a reliability of prediction of about $98 \%$. In none of the cases did we have to fall back on semiquantitative gene dose assessments. We further describe new polymorphisms in the 21hydroxylase region for the enzyme $P v u$ II and $E c o$ R V.
\end{abstract}

\section{Introduction}

Congenital adrenal hyperplasia comprises a number of inborn errors of adrenal steroidogenesis. The most common form ( $95 \%$ of the cases) is due to a steroid 21-hydroxylase (EC 1.14.99.10) deficiency, which causes ineffective cortisol production and results in excessive secretion of the adrenocorticotropic hormone (corticotropin) and consequently of accumulated cortisol precursors, predominantly of 17-hydroxyprogesterone. The result is an abnormally raised production of androgens in the affected adrenals. Classical 21-hydroxylase deficiency includes the simple virilising and salt wasting forms, which lead to prenatal virilisation in affected females, and which occur in about 1 in 7500 births in the Caucasian population (1). In the non-classical form virilisation sets in postnatally. Each form of the disease is inherited as an autosomal trait.

21-Hydroxylase is encoded by a 21-hydroxylase Aand B-gene located between the HLA-DR and B loci on the short arm of chromosome 6 . Each of the genes is connected in a tandem-like fashion with a complement C4 A- and C4 B-gene, respectively. Whereas the 21-hydroxylase A-gene is a pseudogene, the 21-hydroxylase B-gene appears to be the functional gene (2). The arrangement of the genes (3) is shown in figure 1 .

The close linkage between 21-hydroxylase and HLA class I genes permits the latter to be used as a genetic marker in DNA analyses for prenatal diagnosis or carrier testing, provided there is a previously tested index case within the family.

Serological HLA typing and biochemical hormone analyses after amniocentesis can only be performed after the 16th week of pregnancy. With the aid of restriction endonuclease analysis using chorionic villi samples, it is now possible to determine the genotype of foetuses at risk as early as the 8th-9th week of pregnancy by linkage analysis with HLA class I and class II probes. After hybridisation with these probes, some of the resulting bands show a close correlation 


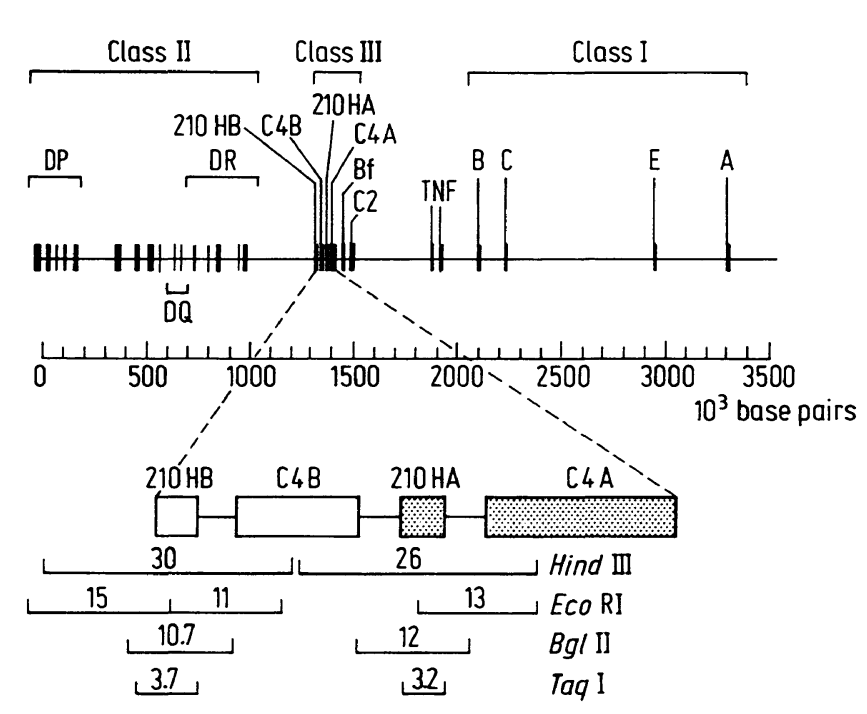

Fig. 1. Gene map of the human HLA class I, II, III region on the short arm of chromosome 6 . The upper part shows the orientation and extension in $10^{3}$ base-pairs $(\mathrm{kbp})$ of the HLA-DP-, DQ-, DR-, 21-hydroxylase B- (21 OHB), C4 B-, 21-hydroxylase A- (21 OHA), C4 B-, Bf- (factor B of complement), C2-, HLA-B-, C- and A-genes. The restriction map of the HLA class III region is shown below on an enlarged scale.

with certain serologically determined alleles from this HLA-region (4). Although linkage between the 21hydroxylase B gene and the HLA-B gene is very close, it was necessary to use probes of the 21-hydroxylase gene locus and the adjacent $\mathrm{C} 4$ locus.

Tab. 1. Clinical and biochemical data of the patients. Abbreviations: (d) stands for abnormally decreased and (i) for abnormally increased values.

\begin{tabular}{llll}
\hline $\begin{array}{l}\text { Patient } \\
\text { no. }\end{array}$ & Age (a) & $\begin{array}{l}\text { Salt- } \\
\text { loss }\end{array}$ & Diagnosed by \\
\hline 1 & 11 & + & (i) $\mathrm{K}(7.88 \mathrm{mmol} / \mathrm{l})$ \\
2 & 17 & + & $\begin{array}{l}\text { (i) } \mathrm{K}(6.7 \mathrm{mmol} / \mathrm{l}) \\
\text { (i) plasma renin activity }\end{array}$ \\
3 & 13 & + & (d) $\mathrm{Na}$ \\
4 & 2 & + & (i) $\mathrm{K}(7.2 \mathrm{mmol} / \mathrm{l})$ \\
5 & 9 & + & (d) $\mathrm{Na}$ \\
& & & (i) $\mathrm{K}(6.8 \mathrm{mmol} / \mathrm{l})$ \\
6 & 14 & + & (d) $\mathrm{Na}(129 \mathrm{mmol} / \mathrm{l})$ \\
7 & 7 & + & (i) $\mathrm{K}(7.5 \mathrm{mmol} / \mathrm{l})$ \\
8 & 7 & + & (i) plasma renin activity \\
9 & 6 & + & (i) plasma renin activity \\
10 & 7 & + & (i) $\mathrm{K}(5.5 \mathrm{mmol} / \mathrm{l})$ \\
11 & 11 & + & (d) $\mathrm{Na}(102 \mathrm{mmol} / \mathrm{l})$ \\
12 & 19 & + & (i) plasma renin activity \\
& & & (i) $\mathrm{K}(6.5 \mathrm{mmol} / \mathrm{l})$ \\
13 & 13 & + & (d) $\mathrm{Na}(124 \mathrm{mmol} / \mathrm{l})$ \\
14 & 4 & + & (i) $\mathrm{K}(8.1 \mathrm{mmol} / \mathrm{l})$ \\
15 & 12 & + & (i) $\mathrm{Na}(116 \mathrm{mmol} / \mathrm{l})$ \\
16 & 19 & + & (i) $\mathrm{K}(7.9 \mathrm{mmol}$ (i) plasma renin activity \\
\hline
\end{tabular}

To evaluate our autoradiographs, we did not use the relative intensities to mark the gene dose, as the Southern blot procedure cannot be regarded as a quantitative method.

We discuss the efficiency of the combined diagnostic use of the HLA class I-, C4- and 21-hydroxylase loci within several families with a known index case, in order to develop a safe strategy for prenatal diagnosis.

\section{Patients and Methods}

In this study we investigated 16 families with the classical salt wasting form of 21-hydroxylase deficiency (tab. 1). The genomic DNA of the patients and their families derived from peripheral white blood cells was digested with restriction endonucleases Taq I, Pvu II, Hind III, Bgl II, EcoR I and EcoR V. The DNA was transferred onto nitrocellulose filters by the Southern blot technique (6). Hybridisation was carried out with inserts of the following probes: pHLA 2 for the HLA class I locus (7), pATA (500) for the complement C4 locus (8) and pC 21/3c for the 21 -hydroxylase locus (2). Washing procedures were performed according to our standard protocol (9).

\section{Results}

Hybridisation patterns obtained after probing with HLA class I probes are so complex that bands may interfere and make it impossible to assign a single band to a specific allele. Therefore we singled out two informative constellations that are shown in figures $2 \mathrm{a}$ and $2 \mathrm{~b}$. In constellation I both parents possess a band which the affected child lacks. This means that both father and mother are heterozygous for this locus and that a sibling of the affected child that lacks the band is also affected. But if the band is present, the proband is phenotypically non-affected (heterozygous or homozygously healthy).

In contrast, constellation II is fully informative in genetic terms, since it is possible to distinguish between the different genotypes. Thus, constellation II allows a differentiation between the heterozygous and homozygous state. The frequency of constellation I within the investigated families is shown in table 2 .

After rehybridisation of the same filters with the C4and 21-hydroxylase probes we used the following variable loci as a source of information. The presence or absence of the 21-hydroxylase B gene-specific 3.7 kb Taq I fragment, the A gene-specific $12.0 \mathrm{~kb} \mathrm{Bgl} \mathrm{II}$ fragment and the $26 \mathrm{~kb}$ Hind III A gene fragment; the occurrence of the $3.9 \mathrm{~kb}, 3.8 \mathrm{~kb}, 3.7 \mathrm{~kb}$ and 3.5 kb $P v u$ II fragments (not yet assigned to either 21hydroxylase $\mathrm{A}$ or $\mathrm{B}$ gene); the $38 \mathrm{~kb}$ and the $35 \mathrm{~kb}$ $E c o$ R V fragments (not yet assigned) and the $11 \mathrm{~kb}$ and $13 \mathrm{~kb}$ EcoR I fragments. 


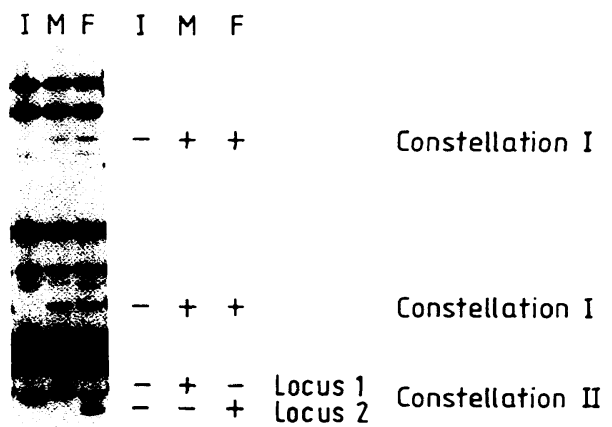

Constellation I

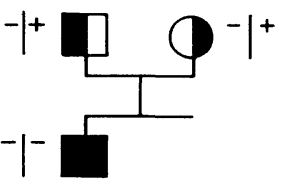

Constellation II

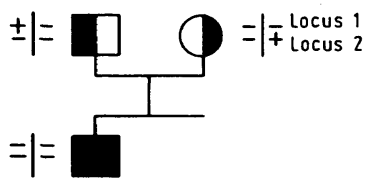

Fig. 2. (a) Polymorphisms of class I-gene restriction fragments. The autoradiograph shows the pattern of Hind III digested genomic DNA hybridised with the HLA class Ispecific DNA probe. Abbreviations: $\mathrm{I}=$ Index case, $\mathrm{M}$ $=$ mother and $F=$ father. The plus stands for the appearance and the minus for the non-appearance of a certain fragment.

(b) The resulting informative pedigree constellations I and II.

During evaluation of the $\mathrm{C} 4 \mathrm{~A}$ and $\mathrm{C} 4 \mathrm{~B}$ loci we obtained information by using the variable Taq I fragments of $7.0 \mathrm{~kb}$ (corresponding to the $\mathrm{C} 4 \mathrm{~A}$ gene) and the $6.4 \mathrm{~kb}, 6.0 \mathrm{~kb}$ and $5.4 \mathrm{~kb}$ fragments, corresponding to the $\mathrm{C} 4 \mathrm{~B}$ gene (8).

Figure 3 shows several examples of similarly informative constellations at the 21-hydroxylase locus with different restriction enzymes.
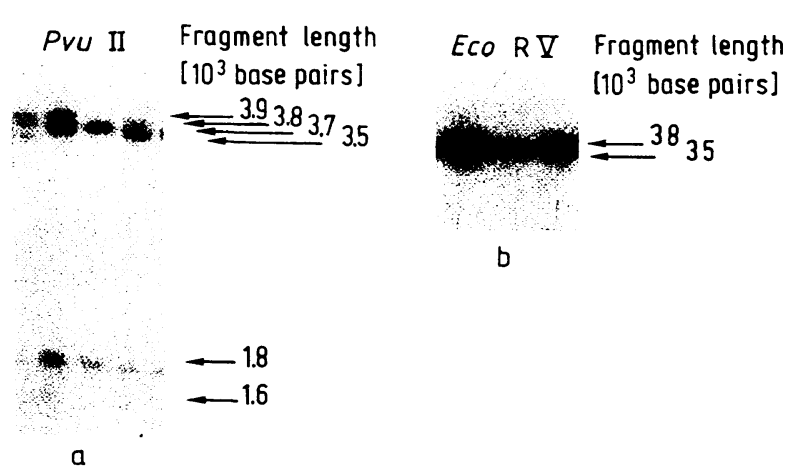

Fig. 3. Restriction fragment patterns from different individuals obtained with the 21-hydroxylase probe. The figures a, b show autoradiographs of the restriction patterns resulting from digestion with $P v u$ II $(3.9,3.8,3.7,3.5 \mathrm{kbp}$ fragments stand for the new variant sites) and EcoR V. The arrows indicate the variable fragments used for genotyping in $10^{3}$ base-pairs $(\mathrm{kbp})$.

Duplications, deletions and gene conversions in the 21-hydroxylase locus would normally require a semiquantitative assessment. But by following our strategy, the number of variable loci is sufficient to dispense with the more unreliable semiquantitative evaluation in prenatal diagnosis and related analytical problems.

With our diagnostic procedure we reached a reliability of prediction of at least $98 \%$ in 4 of the 16 investigated families. In the remaining 12 families the reliability for prediction exceeded $99 \%$; they were informative in the affected gene locus or the adjacent $\mathrm{C} 4$ locus. All the families possessed at least one fully informative constellation at one of the loci.

Tab. 2. Informativity of HLA class I-, 21-hydroxylase-, and complement C4 probes in the 16 investigated families.

Line 2 and 3 show the frequency of the informative constellations I and II obtained with the HLA class I probe within one of the investigated families, including all polymorphic bands resulting from digestion with the six different restriction enzymes.

The plus indicates a similarly informative constellation with 21-hydroxylase- or C4 probe after digestion with the listed restriction enzyme.

\begin{tabular}{|c|c|c|c|c|c|c|c|c|c|c|c|c|c|c|c|c|}
\hline Family/patient no. & 1 & 2 & 3 & 4 & 5 & 6 & 7 & 8 & 9 & 10 & 11 & 12 & 13 & 14 & 15 & 16 \\
\hline \multicolumn{17}{|l|}{ HLA class I probe } \\
\hline Constellation I & 1 & 3 & 1 & 3 & 3 & 8 & 1 & 1 & 1 & 8 & 11 & 13 & 2 & 3 & 8 & 3 \\
\hline Constellation II & 2 & 4 & 2 & 2 & 2 & 8 & 8 & 6 & 2 & 2 & 0 & 2 & 13 & 4 & 2 & 2 \\
\hline \multicolumn{17}{|c|}{ 21-hydroxylase probe } \\
\hline Taq I & & & + & & & + & & & & & & & & + & + & + \\
\hline$P v u$ II & & & + & & & & & + & & & & & & & & + \\
\hline Hind III & & + & & & & & & & & & & & & & & \\
\hline$B g l$ II & & & + & + & & + & & & & & + & & & & + & + \\
\hline EcoR I (13 kbp) & & & + & & & & & & & & & & & & + & + \\
\hline EcoR I (11 kbp) & & + & + & + & & + & & & & & & + & & + & + & + \\
\hline$E c o \mathrm{R} \mathrm{V}$ & & + & & & & & & & + & & & & & & & \\
\hline \multicolumn{17}{|c|}{ Complement $\mathrm{C} 4$ probe } \\
\hline Taq I & + & & + & + & & + & & & & & & & & + & & + \\
\hline
\end{tabular}




\section{Discussion}

Our tools for diagnosing the 21-hydroxylase deficiency were probes of the HLA class I locus, as well as complement $\mathrm{C} 4$ and 21-hydroxylase probes. Our results show that the HLA class I genes are variable to an extent where further semiquantitative assessments become unnecessary. The recombination frequency between the two flanking HLA-B and HLADR loci is considered to be around $1 \%$. The class III C4- and 21-hydroxylase gene complex surrounded in this way covers an area of about $60 \mathrm{~kb}$ from the 5 'end of the $\mathrm{C} 4 \mathrm{~A}$ gene to the $3^{\prime}$ end of the 21-hydroxylase $B$ gene. It is therefore irrelevant as regards the recombination frequency between the HLA class I genes and the 21-hydroxylase $B$ gene, in which orientation the HLA class III complex is arranged. Presently it is impossible to specify an exact recombination rate between HLA-B and 21-hydroxylase B, or between HLA-DR and 21-hydroxylase B. Worldwide, among about two hundred families that have been investigated, only one recombination between the HLA-B and 21-hydroxylase B loci has been found (5).

From a conservative genetic viewpoint the expected recombination rate between HLA-B and HLA-A appears to be no more than $1 \%$. Even under the most unfavourable condition with the distance between the HLA class I genes and the 21-hydroxylase B gene at its greatest, the reliability of prediction would still be more than $98 \%$. Our decision to use HLA class I probes was based on the fact that there are considerably more variable sites in the HLA-A and B loci than in the HLA-DR locus, which appears to be even closer to the functional 21-hydroxylase gene (3).

Additional diagnostic reliability can be gained by subsequent hybridisation of the same filters with $\mathrm{C} 4$ and 21-hydroxylase probes. When working with HLA class I probes it is necessary to submit the agarose gels to an extensive electrophoresis with high separating performance. After hybridisation of the same filters with $\mathrm{C} 4$ and 21-hydroxylase probes, we found additional neutral polymorphisms with $P v u$ II (3.9/ $3.8 / 3.7 / 3.5 \mathrm{~kb}$ ) and with $E c o \mathrm{R} \mathrm{V}$ in the 21-hydroxylase region as shown in figure 3 .

The affected persons in the 5 out of 16 families informative in the Taq I/21-hydroxylase system (see tab. 1) lacked homozygously the $3.7 \mathrm{~kb}$ fragment. We designated families as informative in the $B g l \mathrm{II} / 21$ hydroxylase system in which only the affected persons had a homozygous loss of the $12.0 \mathrm{~kb}$ fragment. Similarly, families in which the affected persons lacked the $26 \mathrm{~kb}$ fragment were informative in the Hind III/ 21-hydroxylase system. Four of the patients homozygously lacking the $3.7 \mathrm{~kb} \mathrm{Taq}$ I fragment had, in addition, a total loss of the $12 \mathrm{~kb} \mathrm{Bgl} \mathrm{II} \mathrm{fragment,}$ and another two had a simultaneous loss of every $\mathrm{C} 4$ B specific Taq I fragment. It has been speculated that this rearrangement is due to an approximately $30 \mathrm{~kb}$ deletion resulting in a non-functional 21-hydroxylase A/B hybrid gene (10).

The patients informative in the $P v u$ II/21-hydroxylase system possessed only the $3.8 \mathrm{~kb}$ fragment, whereas all the non-affected persons had an additional $3.9 \mathrm{~kb}$ fragment. The parents informative in the $E c o \mathrm{R} \mathrm{V} / 21$ hydroxylase system showed a $35 \mathrm{~kb}$ and a $38 \mathrm{~kb}$ fragment, while the child lacked the $38 \mathrm{~kb}$ fragment.

The advantage of this diagnostic strategy, apart from the high reliability of $98-99 \%$, is the fact that a prenatal diagnosis can be performed in the 8 th to 9 th week of pregnancy.

The conventional biochemical and immunological HLA-typing $(11,12,13)$ can only be used from the 16th -20 th week of gestation, and still carries the risk that the HLA antigens will be expressed insufficiently in the amniotic cells.

This early and reliable diagnosis of 21-hydroxylase deficiency allows the introduction of intrauterine therapy before the onset of irreversible virilisation in female foetuses of families analysed according to this new method.

\section{References}

1. Mauthe, J., Laspe, H. \& Knorr, D. (1979) Zur Häufigkeit des kongenitalen adrenogenitalen Syndroms (AGS). Klin. Pädiat. 189, 172-176.

2. White, P. C., Grossberger, D., Onufer, B. J., Chaplin, D. D., New, M. I., Dupont, B. \& Strominger, J. L. (1985) Two genes encoding 21-hydroxylase are located near the genes encoding the fourth component of complement in man. Proc. Natl. Acad. Sci. USA 82, 1089-1093.

3. Dunham, I., Sargent, C. A., Trowsdale, J. \& Campbell, D. (1988) Molecular mapping of the human major histocompatibility complex by pulse-field electrophoresis. Proc. Natl. Acad. Sci. USA 84, 7237-7241.

4. Mornet, E., Boue, J., Raux-Demay, M., Couillin, P., Oury, J. F., Dumez, Y., Dausset, J., Cohen, D. \& Boue, A. (1986) First trimester prenatal diagnosis of 21-hydroxylase deficiency by linkage anaylsis to HLA-DNA probes and by $17-$ hydroxyprogesterone determination. Human. Genet. 73, $358-364$.

5. Matsumoto, T., Kondoh, T., Kamei, T., Yoshimoto, M., Tsuji, Y., Szumori, K., Izumi, R., Iwatani, N. \& Niikawa, N. (1988) Prenatal DNA analysis in four embryos at risk of 21-hydroxylase deficiency. Eur. J. Pediatr. 148, 228232. 
6. Southern, E. M. (1975) Detection of specific sequences among DNA fragments separated by electrophoresis. J. Mol. Biol. 98, 503-517.

7. Sood, A. K., Pereira, D. \& Weissman, S. M. (1981) Isolation and partial nucleotide sequence of a $\mathrm{cDNA}$ clone for human histocompatibility antigen HLA B by use of an oligonucleotide primer. Proc. Natl. Acad. Sci. USA 78, 616-620.

8. Schneider, P. M., Carroll, M. C., Alper, C. A., Rittner, C., Whitehead, A. S., Yunis, E. J. \& Colten, H. R. (1986) Polymorphism of the human complement $\mathrm{C} 4$ and steroid 21-hydroxylase genes. J. Clin. Invest. 78, 650-657.

9. Higuchi, M., Kochhan, L., Schwaab, R., Egli, H., Brackmann, H. H., Horst, J. \& Olek, K. (1989) Molecular defects in hemophilia A: Identification and characterisation of mutations in the factor VIII gene and family analysis. Blood 74, 1045-1051

10. Morel, Y., André, J., Uring-Lambert, B., Hauptmann, G., Betuél, H., Tossi, M., Forest, M. G., David, M., Bertrand, J. \& Miller, W. L. (1989) Rearrangements and point mutations of $\mathrm{P} 450 \mathrm{c} 21$ genes are distinguished by five restriction endonuclease haplotypes identified by a new probing strategy in 57 families with congenital adrenal hyperplasia. J. Clin. Invest. $83,527-536$.
11. Forest, M. G. (1985) Pitfalls in prenatal diagnosis of 21hydroxylase deficiency by amniotic fluid steroid analysis? A six years experience in 102 pregnancies at risk. Ann. N. Y. Acad. Sci. 458, 130-147.

12. Pang, S., Pollak, M. S., Loo, M., Green, O., Nussbaum, R., Clayton, G., Dupont, B. \& New, M. I. (1985) Pitfalls of prenatal diagnosis of 21-hydroxylase deficiency congenital adrenal hyperplasia. Ann. N. Y. Acad. Sci. 458, $111-$ 129.

13. Grosse-Wilde, H., Valentine-Thon, E., Vögeler, U., Passarge, E., Lorenzen, F., Sippell, W. G., Bidlingmaier, F. \& Knorr, D. (1988) HLA-A, B, C, DR typing and 17-OHP determination for second trimester prenatal diagnosis of 21-hydroxylase deficient CAH. Prenat. Diagn. 8, 131-143.

Prof. Dr. K. Olek

Institut für Klinische Biochemie

der Universität Bonn

Sigmund-Freud-Straße 25

D-5300 Bonn 1 
